\title{
Modelling of the Francis turbine runner in power stations. Part I: flow simulation study
}

\author{
R. A. Saeed ${ }^{1}$, A. N. Galybin ${ }^{1}$, V. Popov ${ }^{1} \&$ N. O. Abdulrahim ${ }^{2}$ \\ ${ }^{1}$ Wessex Institute of Technology, UK \\ ${ }^{2}$ Sulaimani University, Iraq
}

\begin{abstract}
This paper presents the results of simulations of the three-dimensional flow through the Francis turbine runner of the Derbendikan power station. A three-dimensional model of the whole Francis turbine runner was prepared according to specifications provided and then the investigated flow model (fluid domain) extracted from the structured model (Francis turbine runner model). Pressure distribution and water velocity have been analysed. The results form input data for the mechanical analysis in the second part. The results show that the maximum absolute pressure is reached $\left(5.387 \times 10^{5} \mathrm{~Pa}\right)$ at the leading edge of the turbine runner.

Keywords: Francis turbine runner, CFD modelling.
\end{abstract}

\section{Introduction}

The flow in hydraulic turbines of the Francis type is quite complicated due to its three-dimensional nature and the curvature of the passages between runner blades. The complexity of the problem requires the application of numerical approaches that are capable of producing accurate results for pressure distributions on the runner and flow velocity. The application of CFD is an efficient way for analysis fluid flow through hydraulic turbines [1, 2, 11]. Nava et al. [3] presented an application of CFD to compute the loads caused by water pressure on a blade of the Francis turbine runner. An experimental approach has been successfully used [4-6] to measure the pressure on the blade, where pressure transducers are embedded in the model runner blades without geometrical alteration. There is a good agreement between numerical simulation and experimental measurements as confirmed by [1,7], who compared the 
numerical flow simulation and experimental evaluation results for the whole Francis turbine. Three-dimensional steady flow analysis of the flow passages from the entrance runner to the outlet in the Francis type turbine has been done by Ikeda et al. [8]. This analysis provides the distributed pressure and water velocity within the computational domain.

In this work the pressure distribution on the blades of the Francis turbine runner and flow velocity were investigated by using Computational Fluid Dynamics (CFD). The investigated Francis turbine runner was of Unit 2 in the Derbendikan hydropower station, one of the major suppliers of electrical power generation in the north of Iraq (Kurdistan region). The investigated turbine runner has the following data [9]: number of runner blades 13, number of guide vanes 24 , rated head $80 \mathrm{~m}$, power output at rated head $83 \mathrm{MW}$, discharge at rated head $113 \mathrm{~m}^{3} / \mathrm{s}$, rotational speed $187.5 \mathrm{rpm}$.

\section{Flow simulations}

In this study, detailed analysis of the fluid flow through the turbine runner is necessary to study the fluid flow conditions - for this purpose the complete turbine runner passageway has been considered. Since the computational domain has a complicated geometry, the analysis of the flow through the whole turbine runner puts high demand on computer memory and CPU time. CFD simulation of all the flow channels of the Francis turbine runner was performed to obtain more accurate results of the pressure distributions on the runner blade.

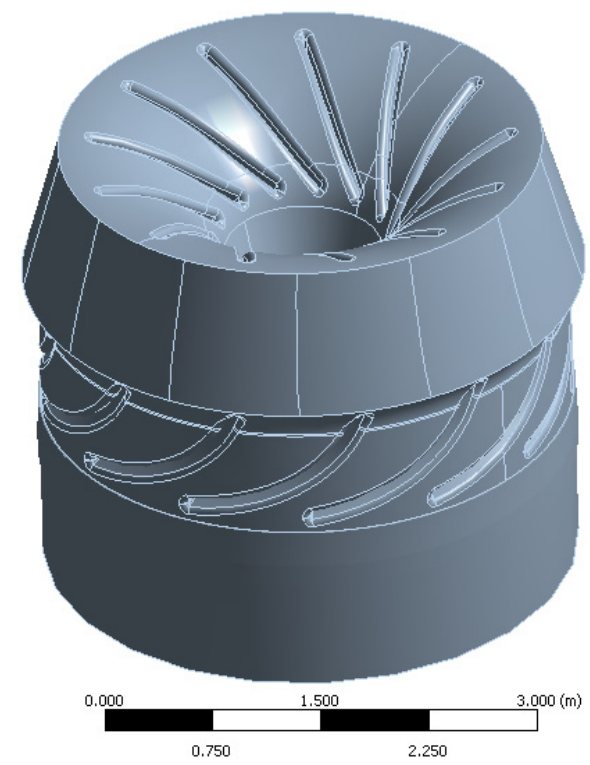

Figure 1: Geometrical model used in the simulation. 


\subsection{Geometrical model}

The first step is building the geometrical model of the flow domain. According to the provided specifications a three-dimensional geometrical model has been created, as shown in Figure 1.

\subsection{Discretization process}

The fluid domain discretization can be accomplished by multiple means, but the most common methods in three-dimensional CFD are based on either tetrahedral or hexahedral finite volumes. In this study, three-dimensional discretization has been used with the finite volume method (FVM) provided by the ANSYS CFX software. In general, the flow simulation software CFX utilizes finite volume method to discretized the computational domain (fluid domain), which is preferred in flow simulations that involve complex geometries [10]. For the computational domain, unstructured 3D tetrahedral meshing has been employed, due to its flexibility when solving complex geometries, (see Figure 2). The whole computational mesh consists of more than 2 million volumes.

In order to accurately simulate the flow conditions of a turbine passage, mesh refinement around the blades edge has been done. The element size in these regions was strictly controlled and particular refinements around the blade end surfaces were made, as shown in Figure 3. It has to be mentioned that large grids are necessary to discrete properly complex flow near the blades. For comparatively fine mesh the steady state simulation leads to a considerable amount of data.

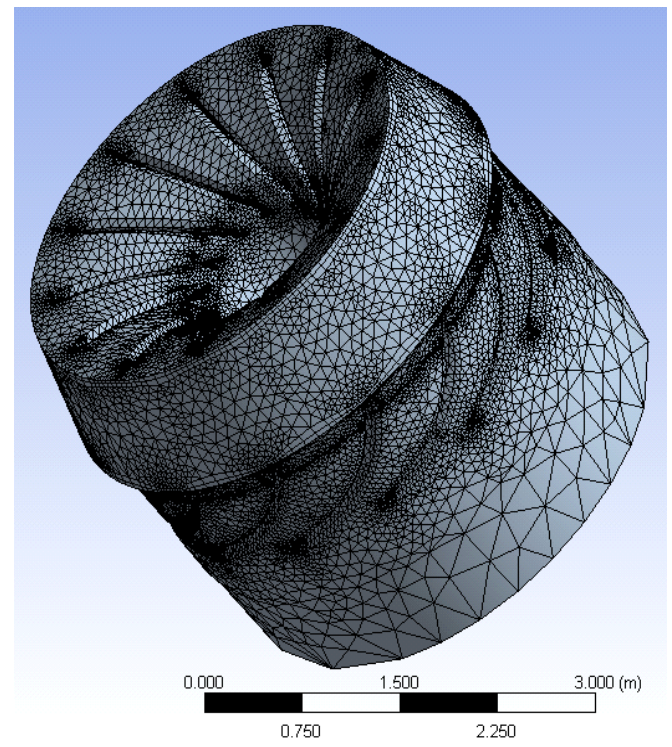

Figure 2: Three-dimensional structured grids of the computational domain. 


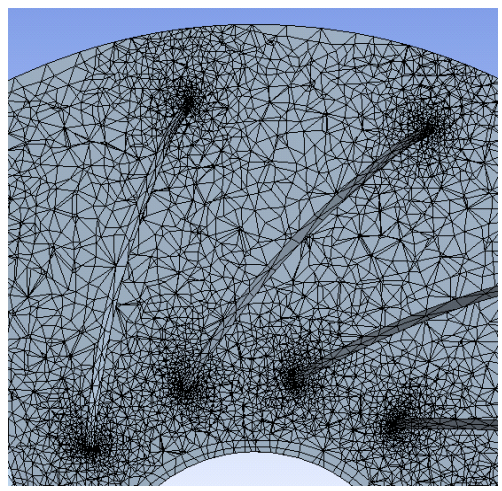

Figure 3: $\quad$ Section view of the gridded computational domain.

\subsection{Numerical modelling of turbulent fluid flow}

For the fluid flow analysis of the entire Francis turbine, the continuity equation and Reynolds averaged Navier-Stokes equation for an incompressible flow has been used in the following form [12]:

$$
\begin{gathered}
\frac{\partial U_{i}}{\partial X_{i}}=0 \\
\frac{\partial U_{i}}{\partial t}+U_{j} \frac{\partial U_{i}}{\partial X_{j}}+\frac{1}{\rho} \frac{\partial P}{\partial X_{i}}-\frac{\partial}{\partial X_{j}}\left(v\left(\frac{\partial U_{i}}{\partial X_{j}}+\frac{\partial U_{j}}{\partial X_{i}}\right)-\tau_{i j}\right)=0
\end{gathered}
$$

where $\mathrm{v}, \mathrm{p}, \mathrm{v}$ and $\rho$ are velocity, pressure, kinematic viscosity and density, respectively, and $\tau_{\mathrm{ij}}$ is the mean viscous stress tensor component, also called the Reynolds stress tensor. The turbulent effects on the flow field are through the Reynolds stresses $\tau_{\mathrm{ij}}$, which are calculated from the turbulence k- $\varepsilon$ model, which is the most often used closure model when modelling turbulent flow. The code uses unstructured finite volume approach, except at the boundaries of the domain, to convert the Reynolds-averaged Navier-Stokes equations to algebraic equations that are further solved numerically.

\subsection{Boundary conditions}

The computations assume steady state incompressible uniform fluid flow in circumferential direction of the turbine runner. The boundary conditions for the inflow velocity components and outlet pressure conditions are described below.

\subsubsection{Inlet boundary conditions}

Inlet boundary conditions at given performance point of the hydraulic turbine runner are derived from an operation condition which include discharge $\mathrm{Q}\left(87 \mathrm{~m}^{3} / \mathrm{s}\right)$, Head $\mathrm{H}(80 \mathrm{~m})$ and output power $\mathrm{P}(65 \mathrm{MW})$. The inlet boundary conditions are developed from inlet velocity profile, because the guide vanes are not included in the computations. Inlet boundary condition consists of the 
tangential or whirl velocity $(18.89 \mathrm{~m} / \mathrm{s})$ and radial velocity or velocity of flow $(7.92 \mathrm{~m} / \mathrm{s})$. Axial velocity for the operating point is set to zero.

\subsubsection{Outlet boundary conditions}

Outlet boundary condition is defined to an opening with an average relative pressure to atmospheric pressure.

\subsection{Resolution phase}

In engineering applications in order to achieve convergence of the solution to an acceptable level, the residual is usually set between four to six orders of magnitude lower than the actual values [10]. Iterative methods are used to solve the corresponding system of algebraic equations, which allows one to characterize the accuracies of approximation solution by analysing the residual. In this study, the RMS residuals settled to a steady state value within 100 iterations. The non-dimensional residual of the momentum and continuity equations was between $10^{-4}$ to $10^{-6}$. The computations took approximately 4 hours to solve this numerical problem on a $2 \mathrm{~GB}$ RAM, 3.0 GHz Pentium 4 computer.

\subsection{Results and discussion}

Three-dimensional analyses of fluid flow through the turbine blades channel have been carried out and the computational results are presented and discussed in the following subsections. The distributions of pressure and water velocity within the computational domain are illustrated in the form of contour and streamlines that are generated with the ANSYS CFX postprocessor.

\subsubsection{Streamlines of the tangential velocity}

The streamlines of the tangential velocity in the fluid domain obtained from the CFD analysis for specific operating conditions as shown in the Figure 4. The symmetrical inflow to the runner can be seen, which results from the uniform flow distribution of the runner inlet. The flow direction is almost radial at the inlet and the streamlines follow the crown shape properly. As observed in the figure, the flow is nearly axial at the centre and the recirculation region extends from the lower part of the crown to the outlet of the computational domain. There is a sharp increase in the magnitude of the velocity close to the trailing edge of the blade near the ring, due to the reduction of area between the blade and the ring.

An example of a flow simulation in a hydraulic turbine runner is shown in Figure 5. The tangential velocities can be observed for an instantaneous operation condition at the inlet of the runner at the guide vane passage. The figure shows streamlines of the tangential velocity starting at different locations in the inlet runner. The tangential velocity component decreases on the blade at the leading edge, which is due to the sharp bend of the flow on the stagnation regions on the blades. The stagnation regions can be observed on a blade near the leading edge. 

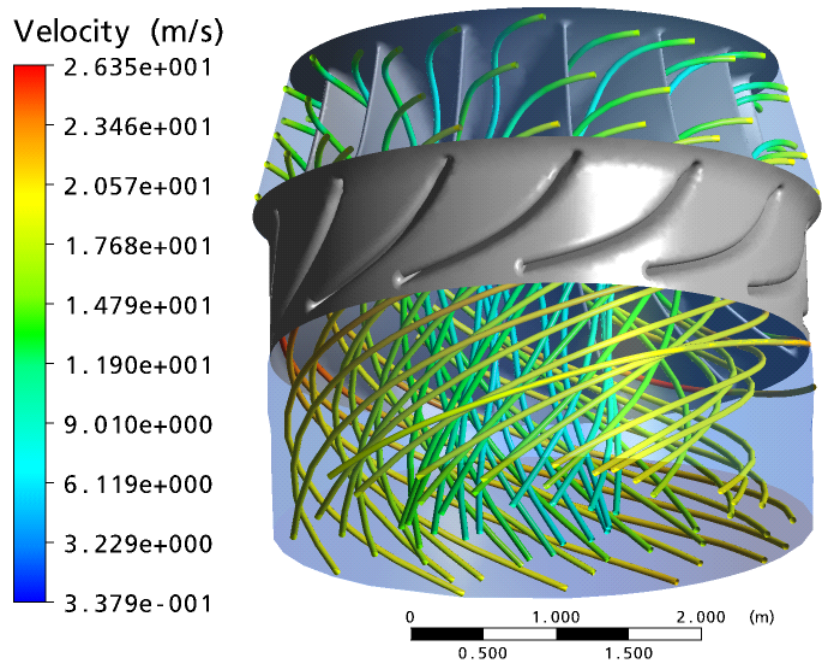

Figure 4: Tangential velocity of the computational domain.

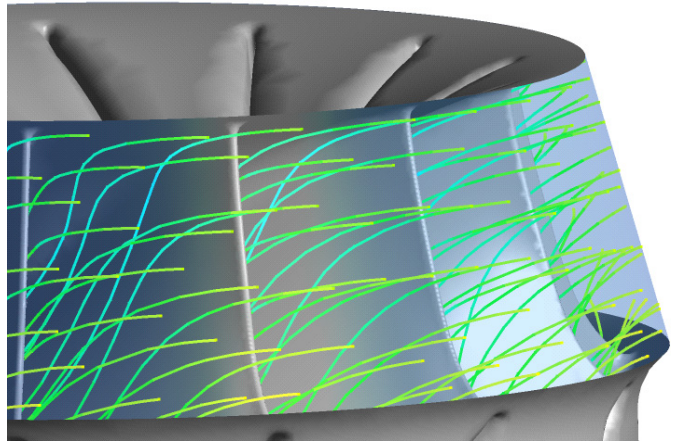

Figure 5: Instantaneous flows in the runner.

\subsubsection{Surface static pressure distribution}

The runner surface pressure distributions obtained from the CFD analysis for specific operating condition shown in the Figure 6. Maximum magnitudes of water pressure are observed at the leading edge of the runner as a result of the stagnation pressure on blades, which results from the rapid decrease in the magnitude of the tangential velocity close to the bend of the flow. Although, reduction of the pressure at the runner outlet is clearly observed, this results of the flow acceleration on the bottom. Symmetrical pressure distribution in circumferential direction can be observed, which results from the uniform flow distribution of the runner inlet. These pressure distributions are later used in the FEM analysis of the turbine runner to find out the mechanical response of the runner to the fluid flow. 


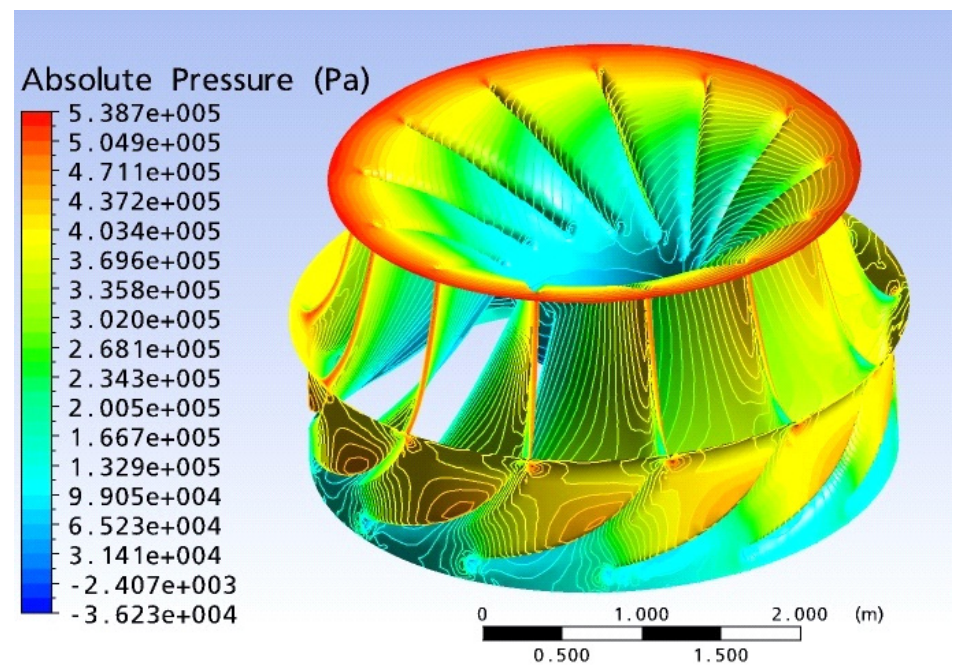

Figure 6: Runner absolute pressure distributions.
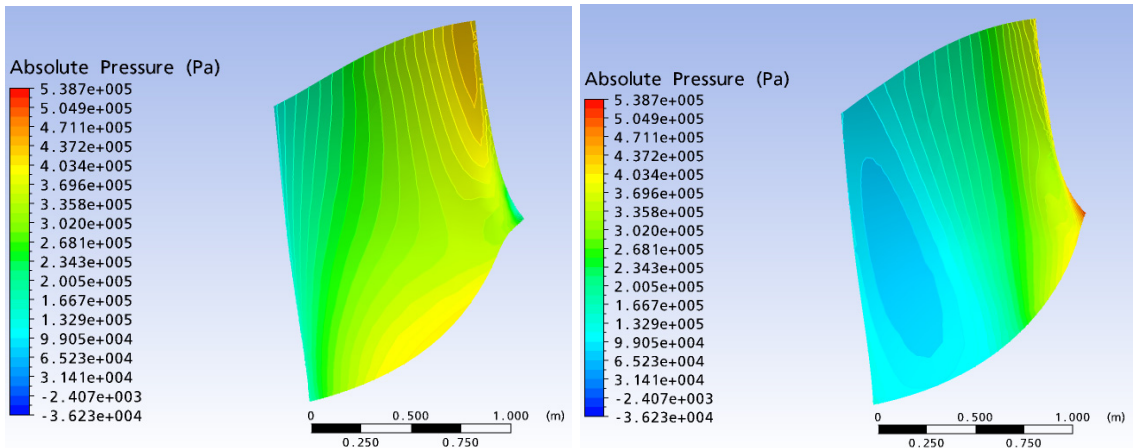

Figure 7: Solutions for pressure on the blades: (a) pressure on the pressure side of the blade; (b) pressure on the suction side of the blade.

Pressure distribution for the pressure and suction side of the runner blades for specific operation condition is shown in Figures 7. Pressure distributions in the pressure side across the height of the runner inlet are non-uniform. At the top of the runner the pressure is quite high whereas at the bottom the pressure is low. The increasing pressure on the blades at the leading edge on both sides is clearly visible due to stagnation. The reduction of pressure on the runner blade suction side near the trailing edge is explained by higher magnitudes of the velocity at the trailing edge. Also, Pressure differences from the pressure and suction side is high and these differences result in a torque on the shaft. 


\section{Conclusions}

The simulation of the 3D steady fluid flow for the complete turbine runner passageway has been performed. Pressure distributions and streamlines of the tangential velocity for a specific operation condition in computational domain have been examined. The pressure profiles are used further to study stresses in the runner.

\section{References}

[1] Èarija Z., Mrša, Z., Complete Francis turbine flow simulation for the whole range of discharges, $4^{\text {th }}$ International Congress, of Croatian Society of Mechanics, Bizovac, Croatia, pp. 105-111, 2003.

[2] Patel, K., Satanee, M., New development of high head Francis turbine at JYOTI LTD. For small hydro power plant, Himalayan Small Hydropower Summit, Dehradun, pp. 307-316, 2006.

[3] Nava, J. M. F., Gómez, O. D., Hernández J. A. R. L., Flow induced stresses in a Francis runner using ANSYS, International ANSYS Conference Proceedings, 2006.

[4] Avellan, F., Etter, S., Gummer, J. H. and Seidel, U., Dynamic pressure measurements on a model turbine runner and their use in preventing runner fatigue failure, $20^{\text {th }}$ IAHR Symposium, Charlotte, North Carolina, USA, 2000.

[5] Farhat, M., Avellan, F. and Seidel, U., Pressure fluctuation measurements in hydro turbine models, The $9^{\text {th }}$ International Symposium on Transport Phenomena and Dynamics of Rotating Machinery, Honolulu, Hawaii, USA, 2002.

[6] Farhat, M., S. Natal, Avellan, F., Paquet, F., Lowys, Py., Couston, M., Onboard measurements of pressure and strain fluctuations in a model of low head Francis turbine part 1: Instrumentation, Proceedings of the $21^{\text {st }}$ IAHR Symposium on Hydraulic Machinery and Systems, Lausanne, pp. 865-872, 2002.

[7] Farhat, M., S. Natal, Avellan, F., Paquet, F., Lowys, Py., Couston, M., Onboard measurements of pressure and strain fluctuations in a model of low head Francis turbine part 2: Measurements and preliminary analysis results, Proceedings of the $21^{\text {st }}$ IAHR Symposium on Hydraulic Machinery and Systems, Lausanne, pp. 873-880, 2002.

[8] Ikeda, K., Inagaki, M., Niikura, K., Oshima, K., 700-m 400-MW Class Ultrahigh-head Pump Turbine, Hitachi Review Vol. 49, No. 2, pp. 81-87, 2000

[9] Fattah, S. S., Khoshnaw, F. M., Saeed, R. A., An investigation about preventing cavitation damage and fatigue failure in Derbendikhan power station, Fluid Structure Interaction and Moving Boundary Problems, Spain, Vol 84, pp. 97-106, 2005.

[10] Hirsch, C., Numerical computation of internal and external flows, John Wiley \& Sons, Ltd, 2007. 
[11] Ruofu, X., Zhengwei, W., Yongyao, L., Dynamic stresses in a Francis turbine runner based on fluid-structure interaction analysis, Tsinghua Science and Technology, Vol. 13, No. 5, pp. 587-592, 2008.

[12] Ruprecht, A., Unsteady flow simulation in hydraulic machinery, Task Quarterly, 187-208, 2002. 